\title{
Uma prova de amor: o uso do cinema como proposta pedagógica para contextualizar o ensino de genética no ensino fundamental
}

Helania Mara Grippa Rui

Patrícia Bastos Leonor

Sidnei Quezada Meireles Leite

Manuella Villar Amado

\section{Resumo}

A genética permeia o cotidiano do cidadão comum e logicamente, dos educandos. Desta forma, é pertinente a inserção desta temática na sala de aula, mediante contextualização e problematização tendo em vista a promoção da reflexão e da criticidade, para além da aquisição dos conhecimentos conceituais. 0 presente trabalho constitui-se em um estudo de caso da aplicação de uma Sequencia Didática baseada no uso do filme "Uma prova de amor", para ensinar conteúdos de genética básica dentro de uma perspectiva CTSA em uma turma de 8 o ano de uma escola pública no município de Vitória. A SD foi baseada na proposta metodológica dos três momentos pedagógicos de Delizoicov e foi desenvolvida a partir da exibição do filme e da realização de um júri simulado. Os resultados apontam que os alunos se apropriaram de muitos conceitos relativos à genética se mostrando capazes de promover uma discussão do papel da ciência na sociedade com reflexões críticas pautadas nos valores sociais vigentes. Sendo assim, a SD analisada nessa pesquisa, baseada na utilização do cinema apresentou-se como uma relevante ferramenta no processo de ensino aprendizagem, quando analisamos a motivação, a interação e consequentemente a alfabetização científica dos alunos.

Palavras-chave: Ensino de genética, Ensino fundamental, Cinema, Sequência Didática.

\section{Abstract}

This paper proposes a discussion about using the movie My sisters Keeper for teaching basic genetics in the 8th grade of elementary school in a public school in Vitória, Espírito Santo. The aim is to analyze the relationship between film, the moot court and the possibilities for more meaningful learning of concepts related to genetics and to point out possibilities of usage in science education and also to propose the discussion of the role of science in society and reflection critique based on social values. The effective participation of students in the processes of research and debates demonstrates the importance of offering different teaching methods, especially those that allow the exercise of leadership, the meaningful involvement of students.

Key words: genetic education, fundamental education, film, didactic sequence 


\section{Introdução}

Os conceitos e termos de genética se fazem presentes na mídia e na cultura popular mediante produções como jogos, filmes e programas sensacionalistas que efetuam testes de DNA. Sendo assim, este tema não está muito distante de nossos alunos que possuem acesso a estes recursos e assistem desenhos animados onde heróis e vilões se estabeleceram graças a mutações genéticas e à engenharia genética.

O pai da genética moderna é um monge austríaco chamado Gregor Mendel que publicou suas descobertas em 1865. De lá para cá, muita coisa já foi realizada, após a identificação da molécula de DNA: decifração do código genético pelo Projeto Genoma Humano, criação de transgênicos e clonagem. Dentre os benefícios da engenharia genética, segundo Barth (2005), podemos, hoje, contar com remédios "sob medida", terapia gênica, terapia com células tronco, testes de paternidade e na área forense, mapeamento e planejamento genético e escolha do sexo de embriões. Estes avanços demandam reflexões, pois existem limites técnicos e éticos a serem respeitados.

Barth (2005) informa que na declaração da UNESCO, o genoma humano é citado como patrimônio da humanidade ressaltando a importância da preservação da vida e da dignidade humana. Para ele:

As possibilidades técnicas obrigam a repensar os valores éticos e orientar as ações da ciência nas suas várias especializações. A ciência cria, inventa, inova; a bioética procura salvaguardar os interesses humanos e a vida, chamando em causa os valores e recordando o dever da responsabilidade $e$ da prudência.(BARTH, 2005, p.390)

Há bem pouco tempo este assunto era classificado como "complexo" para as turmas da faixa etária de 12 e 13 anos dos 8 anos, porém com os citados avanços e as orientações de documentos como os PCN, ciência e tecnologia passaram a ser incluídas nos currículos do ensino fundamental.

A proposta da utilização deste recurso visa aproximar os estudantes desta temática, inserindo-os também em debates sobre ética, ciência e cidadania, discutindo os limites necessários para nossas escolhas, que serão vivenciadas na vida em sociedade.

Neste contexto, o presente trabalho constitui-se em um estudo de caso (LÜDKE; ANDRÉ, 1986, p.17) da aplicação de uma SD baseada no uso do filme "Uma prova de amor", para ensinar conteúdos de genética básica dentro de uma perspectiva CTSA em uma turma de 8 o ano de uma escola pública no município de Vitória.

Percebe-se que o uso de material audiovisual tem sido amplamente difundido nos diversos níveis de ensino, que de certa forma tem facilitado o processo de ensino-aprendizagem. 
Sendo assim, as animações, documentários e vídeos produzidos especialmente para uso em salas de aula têm se multiplicado, mas o acesso a esses materiais nem sempre é possível, contudo, filmes comerciais são muito utilizados na área de Ciências Biológicas, como alternativa para tratar tanto de assuntos relacionados à saúde quanto à educação.

O filme é um recurso de linguagem, servindo para expressar e comunicar ideias, além de ser um recurso tecnológico para adquirir e construir conhecimentos, levando para sala de aula novas realidades e situações-problema, que tendem a serem resolvidos pelos alunos. Quando isso ocorre são desenvolvidos o pensamento lógico, a criatividade, a capacidade de análise crítica, que são características para o desenvolvimento cognitivo (LIBÂNEO apud PIASSI; PIETROCOLA, 2006).

É importante destacar que para educar e tornar o uso de filmes comerciais interessante e contextualizado dentro de uma educação científica é necessário muito mais que reunir pessoas numa sala de vídeo e passar o filme, necessitando de uma argumentação, análise crítica promovendo a aprendizagem.

\section{Fundamentação teórica}

Diante das dificuldades e desafios no processo ensino-aprendizagem na atualidade, os professores tem buscado novas metodologias que ofereçam suporte às suas aulas. Os alunos possuem acesso à diferentes recursos tecnológicos como celular, mp3, internet, e não raras vezes dominam estas mídias de forma mais rápida e adaptada que professores. Desta forma, faz-se necessário, uma aproximação deste universo midiático para a sala de aula como uma forma de contextualização e mediação no ensino.

De acordo com as autoras Krasilchik e Marandino (2004, p.14), "o processo de alfabetização em ciência é contínuo e transcende o período escolar, demandando aquisição permanente de novos conhecimentos". Sendo assim, propõem atividades cujos objetivos centrais são ampliar a compreensão do papel que as ciências e seus conhecimentos representam para nossa sociedade. Sugerem que o acesso a museus, programas de rádio e televisão, revistas, jornais, filmes, entre outros, "devem se colocar como parceiros nessa empreitada de socializar o conhecimento científico de forma crítica para a população". Assim, o professor precisa compreender que "ensinar não é transferir conhecimento, mas criar possibilidades para sua própria produção ou sua construção". (FREIRE, 2008, p.47).

Enquanto escola, temos que "provocar" no aluno um ensino mais significativo, que the desperte interesse ao mesmo tempo integre seu cotidiano à escola. Para Mizukami (1986, p. 59) "Uma abordagem cognitivista implica, dentre outros aspectos, se estudarem cientificamente a aprendizagem como sendo mais que um produto do meio, das pessoas ou de fatores que são externos ao aluno." Sendo assim, ao se utilizar um filme na sala de aula podemos abordar vários conteúdos, principalmente o conteúdo de genética, de maneira mais ampla e multidirecional com 
novos conhecimentos, ampliando-se, desse modo, outros conceitos e promovendo vários saberes.

O aluno é um ser ontológico e epistêmico, não é nulo (DELIZOICOV et al., 2002), interage com o mundo que o cerca, capaz de adquirir conhecimentos fora da escola. Para que se efetive a aprendizagem significativa e sistemática, é necessário que o professor provoque e permeie condições para que o aluno seja um ser crítico, atuante, participante, e acima de tudo tenha uma consciência ampla de determinados termos como ética e a bioética, possibilitando que o aluno se aproprie do conhecimento. É oportuno destacar a importância da alfabetização científica dos alunos, "[...] colocar o assento na necessidade de uma formação científica que permita aos cidadãos participar na tomada de decisões, em assuntos que se relacionam com a ciência e tecnologia." (CACHAPUZ et al., 2005, p. 25)

O uso de filmes como alternativa metodológica, traduz noções e visões com pontos de vistas distintos dentro de contextos sobre a genética, biotecnologia e suas aplicações, melhorando a aprendizagem, vinculando os fenômenos científicos ao dia-a-dia do aluno (OTERO, 2003). Assim sendo, propicia ao professor auxiliar o aluno a refletir criticamente sobre as mensagens recebidas através do filme.

A imagem visual é uma representação analógica. Aprender através de imagens corresponde a signos. Vigotski (2003, p. 71) se refere, "A analogia básica entre signo e instrumento repousa na função mediadora que os caracteriza." Há uma relação entre signoatividade mediadora-instrumentos. Portanto, o ato de assistir um filme, representa signos para o aluno, quando ele começa a apreender o significado representado, compartilhado socialmente e principalmente mediado ele internaliza em uma influência mútua de significados.

Desta forma, o uso de vídeo/DVD em sala de aula é um instrumento que pode auxiliar a ação pedagógica, ajuda a relacionar os fatos com mundo real. Nesta tecnologia estão os movimentos, as cores, o texto, a linguagem, o belo, o feio, o conhecido e o desconhecido. Moran (1995, p. 3) menciona:

O vídeo nos seduz, informa, entretém, projeta em outras realidades (no imaginário) em outros tempos e espaços. O vídeo combina a comunicação sensorial-cinestésica, com a audiovisual, a intuição com a lógica, a emoção com a razão. Combina, mas começa pelo sensorial, pelo emocional e pelo intuitivo, para atingir posteriormente o racional.

A partir desta concepção é claramente visto que se aprende através de signos, sendo assim, com o uso de filmes, se torna uma ferramenta para as atividades pedagógicas ajudando o aluno na formação de novos conceitos. Os alunos não devem aceitar passivamente o que lhes é oferecido, devem ser capazes de julgar com valores éticos e morais, refletindo criticamente as inúmeras mensagens recebidas (MORAES, 2008). 
Sendo assim, para ir além de comentários do filme foi proposto nesse trabalho um júri simulado, de forma a provocar no aluno a sua participação mais ativa, permitindo que este tome decisões, a partir de um conjunto de atividades que possibilitem o conhecimento de amplos conceitos sobre o tema, e que permita alavancar uma problematização para a formação de opinião cidadã pautada no conhecimento científico e não em saberes populares, garantindo uma tomada de decisão consciente.

Sob este aspecto, Teixeira (2003) sente a ausência da análise de educadores e da perspectiva em relação a filmes que tratam de temas educacionais. Sabe-se que os filmes não foram feitos direcionados à área educacional, mas a análise de um determinado filme pode propiciar reflexões e mudanças de valores em alguns temas importantes para a vida do aluno como o filme "Uma prova de amor".

Desta forma, ao ser proposto como atividade pedagógica o filme "Uma prova de amor" buscamos apropriação pelos alunos de novas expressões e significados de conceitos possibilitando o enriquecimento do conhecimento, principalmente contribuindo para que estes possam interagir melhor com o mundo fora da escola. Assim, não cabe ao professor transmitir informações, mas, trabalhar a partir das percepções de mundo dos alunos - que são muitas e, geralmente, desordenadas - possibilitando uma análise crítica e uma organização dessas percepções, fazendo assim o aluno sujeito do seu conhecimento.

\section{Procedimentos metodológicos}

\subsection{A Pesquisa}

Esta pesquisa é um estudo de caso, de caráter qualitativo, que visa propor e avaliar uma sequência didática (SD) sobre o ensino de genética e sua relação com a cidadania.

A SD foi baseada na proposta metodológica dos três momentos pedagógicos de Delizoicov et al. (2002), que são identificados como problematização (P), organização do conhecimento(OC) e aplicação do conhecimento $(\mathrm{AC})$, que se opõe à prática tradicional memorística do ensino.

Segundo estes autores, a problematização intenciona que os alunos sejam desafiados a expor seus conhecimentos prévios e reflexões sobre a temática, permitindo que o aluno sinta a necessidade de aquisição do conhecimento para enfrentar o problema.

A organização do conhecimento dá-se através da seleção e organização dos conhecimentos necessários para a compreensão dos temas e da problematização inicial, que pode acontecer por meio de atividades diversas. Já a aplicação do conhecimento pretende "capacitar os alunos ao emprego dos conhecimentos, no intuito de formá-los para que articulem constante e rotineiramente, a conceituação científica com situações reais" (DELIZOICOV et al., 2002, p. 202). 
O cinema sempre foi um grande veículo de divulgação dos avanços da ciência. Não apenas documentários e ficções científicas exprimem conhecimentos desejados e alcançados, mas até dramas (profundos ou tolos) e comédias revelam a penetração da ciência em nossa cultura (OLIVEIRA, 2005).

Sendo assim, a SD foi direcionada para o uso do cinema, com a exibição do filme "Uma prova de amor" além de propor algumas outras atividades que tiveram como finalidade direcionar o ensino dentro de um contexto onde os alunos fossem capazes de buscar e se apropriar do conhecimento científico de forma crítica e contextualizada.

\subsection{Local e Sujeitos}

O local da pesquisa foi a Escola Municipal de Ensino Fundamental Suzete Cuendet, localizada na Rua Otto ramos, número 69, Maruípe, Vitória, Espírito Santo. Os sujeitos envolvidos foram alunos de uma turma do 8 o ano do ensino fundamental matutino composta por 33 alunos.

\subsection{Descrição da Sequência Didática}

A SD foi organizada tendo como problematização a exibição do filme "Prova de amor" (Figura 1) levantando questionamentos e promovendo a investigação. Já na fase seguinte, a organização do conhecimento foi proporcionado pela pesquisa no laboratório de informática, entrevistas a oncologistas e geneticistas, com produção de relatórios e textos. A execução do júri simulado compreende a aplicação do conhecimento onde os alunos representam papéis sociais como: advogado, assistentes sociais e médicos.

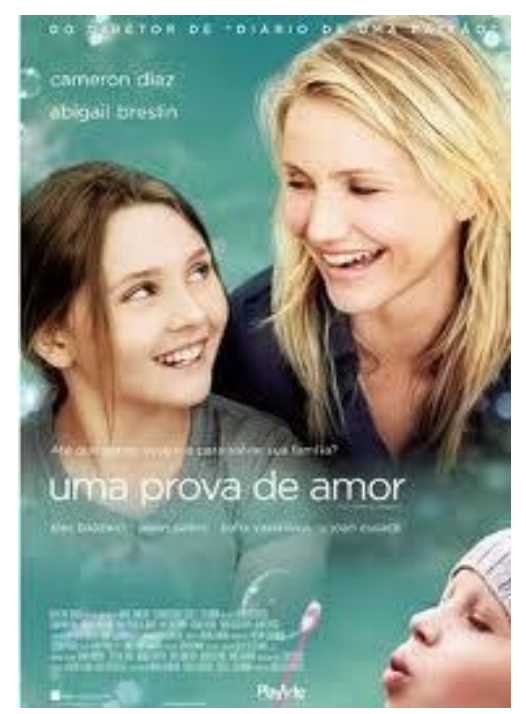

Figura 1 - Capa do Filme "Uma prova de amor" 
O filme foi exibido na lousa digital do laboratório de informática (Figura 2), em duas sessões, com pausa na sequência da audiência jurídica, de forma que a turma não assistiu ao final do filme nesse primeiro momento para que não houvesse interferência no julgamento de valores morais e éticos proposto pelo júri simulado, que seria realizado a seguir. O filme "Uma prova de amor" é uma produção americana de setembro de 2009, do gênero drama, colorido, com 109min de duração, dirigido por Nick Cassavetes, produzido por Scot Goldman, Mark Johnson e Chuk Pacheco, distribuído pela PlayArte, com roteiro de Nick Cassavetes e Jeremy Leven baseado no livro de JodiPicout. A classificação é 12 anos.

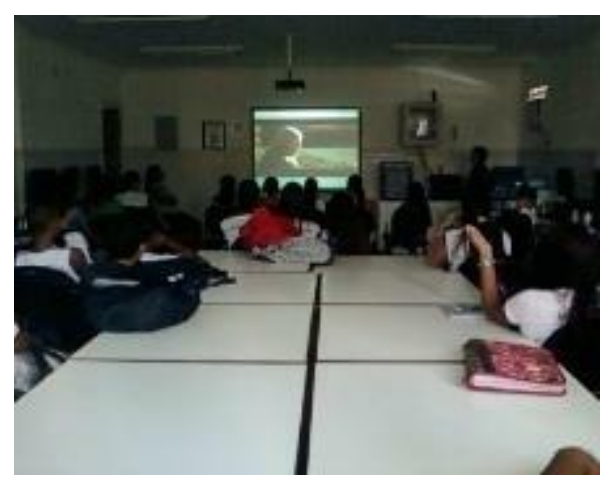

Figura 2 -Alunos assistem ao filme no laboratório de informática

O filme conta a história de Anna Fritzgerald, um bebê geneticamente projetado para ser doadora compatível com sua irmã, Kate, doente de câncer. Por 11 anos, ela foi submetida a inúmeras consultas médicas, cirurgias e transfusões para que sua irmã mais velha, Kate, pudesse de alguma forma, lutar contra a leucemia que a atingiu ainda na infância. Tudo transcorre normalmente até que Anna contrata um advogado famoso, para conseguir a emancipação médica dos pais. O filme desenvolve um dilema ético e traz impactos emocionais quando deixa uma dúvida a ser respondida pelo expectador: a decisão de Anna é certa ou errada? E quanto aos pais, até aonde foi acertada a decisão de dispor do corpo da filha mais nova para salvar a vida de sua irmã?

A leucemia pró-mielocítica aguda, de que trata o filme, é um subtipo da leucemia mielóide aguda, um câncer do sangue e da medula, que ocorre devido a uma acumulação anormal de granulócitos em tufos na medula óssea, ou seja, não ocorre a maturação destas células. Isto acontece quando ocorre uma translocação cromossômica envolvendo o gene receptor alfa do ácido retinóico RARalfa ou RARA. Em 95\% dos casos o receptor alfa do cromossomo 17 sofre translocação com o gene da leucemia promielocítica do cromossomo 15(PML)t(15;17)(q22;q12), ou ainda raramente, entre os cromossomos 5 ou 11 e o 17 (JÁCOMO et al.,2008). O diagnóstico é feito com base a análise do aspirado da biópsia de medula óssea por reação em cadeia de polimerase para fusão do gene RAR alfa e também da citogenética convencional de sangue periférico ou da medula óssea. Dentre os sintomas podemos apontar fraqueza, perda de peso, febre, anemia e a petéquia que se caracteriza por um pequeno ponto 
vermelho no corpo (na pele ou mucosas), causado por uma pequena hemorragia de vasos sanguíneos e anemia. $O$ tratamento hoje em dia é feito com drogas de última geração e ainda transplante de células- tronco e de medula óssea, sendo que para doadores aparentados, a compatibilidade é maior. No filme a única solução proposta para Kate Fritzgerald, uma vez que não havia este doador, foi o nascimento de um bebê projetado para estes fins.

Dentro de um contexto real, em fevereiro de 2012 nasceu o primeiro bebê projetado brasileiro, a menina Vitória, concebida para ser doadora de medula óssea para a irmã que sofre de Talassemia aguda. Daí, a relevância da discussão desta temática, pois não se trata somente de um filme e suposições, mas de possibilidades reais de cura de doenças alcançadas graças à engenharia genética, assim como as suas implicações éticas.

Logo após a semana de exibição da primeira parte do filme, conceitos de genética básica, entre outros como bioética, transplante de órgãos e de medula óssea, compatibilidade sanguínea e histológica, leucócitos, emancipação médica, leucemia, leucemia pró-mielocítica aguda, bebês projetados, fertilização artificial, dentre outros, foram pesquisados pelos alunos através de livros especializados, sites da internet e por entrevistas a profissionais de saúde, como forma de buscar informações relevantes, para embasar argumentos com conhecimentos científicos e jurídicos durante o júri simulado.

O júri simulado realizou-se também no laboratório de informática da escola (Figura 2), com a participação da mediadora e, professora de ciências. A turma se dividiu em dois grupos: um representando a menina Anna Fritzgerald, que no filme processa seus pais pelo direito de emancipação médica e outro, representando a mãe, Sara Fritzgerald, que busca a todo custo, salvar sua filha mais velha, doente de câncer. Cada grupo possuía um médico, um advogado e um assistente social, papel representado pelos próprios alunos para mediação das discussões. Os jurados foram representados pelas professoras de ciências e informática e mais dois alunos. Após o júri simulado os alunos terminaram de assistir o restante do filme.

Esta SD foi avaliada tomando-se como critério a unidade e a participação dos alunos em grupo, a habilidade de argumentação e, embasamento teórico e apropriação dos conteúdos de biologia em questão.

\section{4 Autorizações}

Este trabalho de pesquisa foi devidamente autorizado pelas professoras regentes, pela direção da escola e pelos alunos, tanto para sua realização, quanto para divulgação dos resultados, tendo por fins, objetivos pedagógicos e científicos. 


\section{Análise da pesquisa}

Desde a proposição da exibição deste filme em questão, percebemos o interesse diferenciado dos alunos, ficando evidenciado a sensibilidade aos sintomas manifestado pela doente, e a reflexão sobre o comportamento de adolescentes que passam por conflitos emotivos..

A maioria destes alunos se posicionou a favor de Anna desde o início, solidarizando-se com a busca de autonomia e liberdade com o próprio corpo, mas também evidenciando a típica rebeldia desta faixa etária contra a autoridade seus pais.

A cena da família na praia comoveu a todos; percebe-se aqui a importância dos laços familiares numa clientela em que os lares, em sua maioria, foram dilacerados.

Um exemplo da participação dos alunos pode ser observado nos relatos transcritos no quadro abaixo:

Os alunos foram provocados quanto à situação psicossocial dos outros filhos do casal Fritzgerald. Ao que uma aluna que representava uma assistente social, afirmou:

"O Jess apresenta dislexia por causa do abandono dos pais"

Foi imediatamente interpelada :

"Que nada, isto é genético! A criança nasce com este problema"

e deu explicações sobre a doença. Um aluno pergunta:

"O que é dislexia?

Ao que outro responde:

Meu irmão apresentou dificuldades de ler escrever e a escola falou que. ele tinha dislexia, que é uma dificuldade em identificar as letras..

Percebemos durante o processo que a pesquisa realizada por eles fundamentou os debates, conforme observamos nos quadros seguintes:

Durante o júri, o advogado de Anna Fritzgerald questiona a médica do grupo contrário sobre a necessidade do transplante de medula, e obtém a seguinte resposta:

"A leucemia ocorre em todas as faixas etárias, aumentando com a idade, entre 45 a 55anos, mais no sexo masculino. $O$ transplante de medula é um recurso terapêutico que aumenta a sobrevida em cinco anos ou mais se o diagnóstico for precoce."

Um dos jurados pergunta o que é translocação. A médica do grupo que representa a mãe de Anna, responde: 
"Ocorre ali uma mudança nos cromossomos 15 e 17; uma perninha de num passa para o outro, causando a doença."

Durante o júri simulado os alunos foram provocados a explicar e contextualizar questões como a fertilização artificial, como nasce um bebê projetado e quais foram as implicações sócioafetivas desta doença no seio da família Fritzgerald.

O fato dos pais de Kate optarem por um bebê projetado para salvar sua vida, levou a discussão sobre bioética, sobre os sentimentos e pensamentos dos alunos acerca desta questão. Muitos se colocaram no lugar da adolescente Anna, que tem consciência de sua situação: um ser que foi geneticamente selecionado para ser compatível com a irmã.

A bioética tem por objetivo associar a biologia à ética, por meio de uma prática interdisciplinar, onde médicos juristas, advogados, cientistas, religiosos, atuem em comum acordo para estabelecer um conjunto de normas aceitável para todos e isto decorre dos avanços consideráveis da medicina e da biologia na atualidade.

Para Chassot (2001, p. 99)

Parece que se fará Alfabetização Científica quando o ensino de ciências contribuir para a compreensão de conhecimentos, procedimentos e valores que permitam aos estudantes tomar decisões e perceber tanto as muitas utilidades da ciência e suas aplicações na melhoria da qualidade de vida, quanto as limitações e consequências negativas de seu desenvolvimento.

Para este autor, o desafio de discutir-se a ética nestes casos não é individual, mas pertinente à toda a sociedade, que tem o direito de estar informada o suficiente para debater determinadas questões como transgênicos, armamento nuclear, dentre outras. Dessa forma a SD desenvolvida nesse estudo está dentro da perspectiva do ensino de ciências da atualidade que abrange discussões pertinentes ao eixo CTSA, visando a formação de um aluno que saiba ler o mundo em seu entorno e contribuir de forma crítica e racional como membro atuante da sociedade.

\section{Considerações finais}

Ao promover uma prática pedagógica com a utilização do cinema na sala de aula, ficou constatado que quando bem planejado a sua utilização e combinação com outras ferramentas como o júri simulado estes se tornam importantes no processo ensino-aprendizagem.

Sendo assim, os interesses dos alunos devem ser direcionados e motivados constantemente, buscando-se saber exatamente o que se quer que o aluno aprenda realmente e de todas as possibilidades que se dispõem para que isso aconteça. 
O filme sozinho não abrange os conteúdos, como foi o caso da necessidade das pesquisas em laboratório de informática, para buscar novos subsídios para um assunto tão amplo, somente o filme, não daria conta de tantas respostas, reflexões, questionamentos sobre a genética, biotecnologia, engenharia genética, patrimônio genético, mas serviu para alavancar as indagações e principalmente a compreensão dos conceitos, tendo contribuído para muitas reflexões e múltiplas visões, além de propiciar uma autonomia de opiniões dos alunos dentro dos preceitos éticos e morais, que é o que se pretende na proposta de alfabetização científica.

Percebemos que ainda hoje, o câncer é visto como tabu e com preconceito por parte de algumas pessoas e por isso é importante que a escola proporcione a aquisição de informações seguras sobre esta doença e suas formas de tratamento, auxiliando no esclarecimento de mitos e na divulgação dos benefícios dos transplantes e doação de órgãos. 


\section{Referências}

CACHAPUZ, A.; GIL-PÉREZ, D.; CARVALHO, P. M. A.; PRAIA, J.; VILCHES, A. A necessária renovação do ensino de ciências. São Paulo: Cortez, 2005.263 p.

CHASSOT, Ático. A ciência através dos tempos.São Paulo:Moderna, 2004.

DELIZOICOV, Demétrio; ANGOTTI, J. A.; PERNAMBUCO, M. M. Ensino de ciências: fundamentos e métodos. São Paulo: Cortez, 2002. 364 p.

JÁCOMO R. H; FIGUEIREDO-PONTES, L. L; REGO,E. M. Do paradigma molecular ao impacto no prognóstico: uma visão da leucemia promielocítica aguda. Revista Associação Médica Brasileira, São Paulo, p.82-89,2008.

LÜDKE, Menga e ANDRÉ, Marli E. D. A. Pesquisa em educação: abordagens qualitativas.São Paulo: EPU, 1986. KRASILCHIC, M. Prática de ensino de biologia. São Paulo: Editora da Universidade de São Paulo, 2004. 197 p.

KRASILCHIK, M.; MARANDINO. M. Ensino de ciências e cidadania. São Paulo: Moderna, 2004. LEITE, Ligia Silva (Coord.). Tecnologia educacional: descubra suas possibilidades na sala de aula. Petrópolis: Vozes, 2003. 119 p.

MANDARINO, M. C. Freire. Organizando o trabalho com vídeo em sala de aula. Revista Eletrônica em Ciências Humanas. Ano 01, n.1, 2002.

MIZUKAMI, M. G. N. Ensino: As abordagens do processo. São Paulo, EPU, 1986.

MORAES, C. De um mundo da escola para uma escola do mundo: reflexão sobre meios e sobre fins. Comunicação \& Educação, v. 10, n. 3, 2008.

MORAN, José Manoel.O vídeo na sala de aula. Revista comunicação e educação, São Paulo, v. 2,p. 27-35, 1995.

OLIVEIRA, Bernardo Jefferson de. História da Ciência no cinema. Belo Horizonte: Argumentum, 2005.

OTERO, R. M. Imagines e Investigación em Enseñanza de las Ciências. PIDEC: Textos de apoio do Programa Internacional de Doutorado em Ensino de Ciências da Universidade de Burgos (Convênio UFRGS), Porto Alegre, v. 5, 2003.

PIASSI, L. P.; PIETROCOLA, M. Possibilidades dos filmes de ficção científica como recurso didático em aulas de física: a construção de um instrumento de análise. In: Encontro de Pesquisa em Ensino de Física, 10, São Paulo. Anais... São Paulo: Faculdade de educação da USP, 2006. TEIXEIRA, Inês assunção de Castro (Org.). A escola vai ao cinema. Belo Horizonte: Autêntica, 2003. 220 p. VIGOSTKI, L.S. A formação social da mente. 6.ed. São Paulo: Martins Fontes, 1998. 
Helania Mara Grippa Rui - Instituto Federal do Espírito Santo Vitória - Espírito Santo helaniamara@hotmail.com

Patrícia Bastos Leonor - Instituto Federal do Espírito Santo Vitória - Espírito Santo patriciabl5@yahoo.com.br

Sidnei Quezada Meireles Leite - Instituto Federal do Espírito Santo Vitória - Espírito Santo sidneiquezada@gmail.co

Manuella Villar Amado - Instituto Federal do Espírito Santo Vitória - Espírito Santo manuellaamado@gmail.com 